\title{
COMPARISON OF OPEN VERSUS LAPAROSCOPIC APPENDECTOMY IN TERMS OF POST OPERATIVE PAIN AND OPERATIVE DURATION.
}

\footnotetext{
1. MBBS, FCPS, MRCS

Senior Registrar Department of Surgical Unit 1 Allied Hospital Faisalabad

2. MBBS, FCPS

Senior Registrar

Department of Surgical Unit 1 Allied Hospital Faisalabad.

3. MBBS, FCPS

Senior Registrar

Department of Surgical Unit 1 Allied Hospital Faisalabad.

4. MBBS, FCPS

Professor

Department of Surgical Unit 1 Allied Hospital Faisalabad.

5. MBBS, FCPS

Assistant Professor

Department of Surgical Unit 1

Allied Hospital Faisalabad.
}

Correspondence Address:

Dr. Osman Riaz

Department of Surgical Unit 1

Allied Hospital Faisalabad.

osmanriazdab@gmail.com

Article received on:

09/04/2019

Accepted for publication:

15/07/2019

Received after proof reading:

30/09/2019

\begin{abstract}
Saddaqat Hayat', Osman Riaz², Muhammad Usman³, Muhammad Faisal Bilal Lodhi', Asrar Ahmad Khan ${ }^{5}$

ABSTRACT... Objectives: To measure the results of open appendectomy and laparoscopic appendectomy regarding mean postoperative pain and mean operative duration in the treatment of acute appendicitis. Study Design: Randomized clinical trial. Setting: Surgical unit Allied hospital Faisalabad. Period: June 2016 to December 2016. Material and Methods: 70 patients with appendicitis were included in the study through non-probability consecutive sampling. Patients with history of long standing pain, intake of analgesics ( $>3$ times per week for $>3$ months) before surgery and patients in whom laparoscopic surgery was contraindicated were excluded. Patients were randomized in group A and group B. Open appendectomy was done in group A and laparoscopic appendectomy was carried in group B. Outcomes in terms of post-operative pain at visual analogue scale and operating time in minutes was measured. Results: Mean age was 28.50 years with standard deviation of 12.283 . There were 32 (45.71\%) patients were male and 38 (54.29\%) patients were females. Post-Operative pain was $7.34 \pm 2.014$ in group $A$ and $3 \pm 1.94$ in group $B$ with $p$-value $=0.0001$. Operative time in group $A$ was $42.33 \pm 4.25$ minutes and group $B$ had time of $34.48 \pm 3.5$ minutes with $p$-value $=0.0001$. Conclusion: Laparoscopic appendectomy is superior to open appendectomy considering pain after surgery and time of surgery in patients with appendicitis.
\end{abstract}

Key words: $\quad$ Appendicitis, Laparoscopic Appendectomy (LA), Open Appendectomy (OA).

Article Citation: Hayat S, Riaz O, Usman M, Lodhi MFB, Khan AA. Comparison of postoperative pain and operative duration in cases of open versus laparoscopic appendectomy. Professional Med J 2019; 26(10):1706-1711. DOI: 10.29309/TPMJ/2019.26.10.3534

\section{INTRODUCTION}

Appendicitis is the leading cause of acute abdomen in young adults. ${ }^{1,2}$ The life time risk of acute appendicitis in males is $8.6 \%$ and females $6.7 \% .^{3}$ Appendicectomy is one of the frequent surgical procedures and is about $1 \%$ of all surgical operations. ${ }^{4}$ In 1889 , Charles McBurney introduced open appendectomy which became gold standard in management of appendicitis.

Endoscopy has revolutionized the concept of appendectomy using laparoscope. First laparoscopic appendectomy was performed by Semn in $1983 .^{3}$ After that, laparoscopic appendectomy is considered as convenient and secured operation and acquired global acceptance. $^{5}$

Some researchers claim that appendectomy done by laparoscopy is speedy and is more comfortable for patients leading to short duration in hospital, rapid recovery, less traumatic, decrease wound infections and having good cosmetics results. ${ }^{6}$ However, laparoscopic appendectomy may need more cost because of specific equipments, longer operative time. It may be associated with a high chance of abscess in abdomen, more in severe cases like ruptured appendicitis. ${ }^{6}$ Longer operative time for laparoscopic appendectomy as shown by previous studies is currently not accepted. ${ }^{5}$ The reason behind increased operative time was because of less expertise in endoscopic surgery and less flexible laparoscopic instruments.

Pain (overall level) is significantly less in patients having Laparoscopic appendectomy than having open appendectomy $(P=0004) .^{7,8}$ Mean postoperative pain according to Visual analogue score at 48 hours for Open appendectomy is $4.6 \pm 0.8$ and $1.5 \pm 0.6$ for Laparoscopic 
appendectomy. ${ }^{8,9}$

In south east asia, only some research has been done to compare open and laparoscopic appendecectomy. ${ }^{10}$

The objective of this study was to provide guidelines to do increase number of appendectomies using laparoscope. The results of our research clearly indicate that laparoscopic appendectomy has same time duration as open appendectomy and much beneficial for patients in terms of postoperative pain.

\section{OBJECTIVE}

To measure the result of open appendectomy and laparoscopic appendectomy regarding mean postoperative pain and mean operative duration in the treatment of acute appendicitis.

\section{METHODOLOGY}

This research was conducted in department of surgery, Allied Hospital, Faisalabad, from June 2016 to December 2016. Sampling technique was non-probability consecutive sampling. Sample size was calculated by using WHO sample size calculator for two means anticipated population mean $=48.26$, test value of population mean $=31.36$, pooled standard deviation $=12.14$, level of significance $=5 \%$, power of study $=90 \%$ and sample size $=70$ (35 in each group).

The patients having acute appendicitis of aged 13-60 years were included. The acute appendicitis was diagnosed with complaint of right iliac fossa pain with nausea/vomiting, right iliac fossa tenderness on clinical examination and leukocytosis $>10,000$ cells $/ \mathrm{mm}$ on investigations. Patients with history of long standing pain, intake of analgesics ( $>3$ times per week for $>3$ months) before surgery and patients in whom laparoscopic surgery was contraindicated were excluded.

Approval from the hospital ethical committee was taken. After taking informed approval, patients were assigned in two groups $(A / B)$ randomly. Patients in Group A had appendectomy by open technique and in Group B by laparoscopy. Postoperative pain was noted and scored after 48 hours of surgery on a visual analogue scale (VAS) consisting of a 10-cm-long horizontal line without graduations varying from "no pain at all" on the left side to "unbearable pain" on the right side. Afterward, the VAS was be scored by measuring the length in millimeters left of the patient's mark. In both groups, the operative duration was taken from skin incision to skin closure. Performa was filled to collect all findings.

SPSS version-20 was used for data analyses. Mean and standard deviation was calculated for continuous variables like age, operative time and pain and independent t-test was applied. Frequencies and percentages were calculated for categorical variables like gender. Statistical significance was set at $p$ value $\leq 0.05$. Stratification was done to control effect modifier (age and gender). Independent t-test was used after stratification.

\section{RESULTS}

In six months from June 2016, seventy patients were included in this research (35 in group $A$ and 35 in group B).

Age range was $13-59$ years in both groups. Mean and standard deviation for age was 28.50 years and12.283. Mean age in group A was 27.74 \pm 12.04 years and in group B was $29.26 \pm 12.65$ years.

$32(45.71 \%)$ patients were male and 38 (54.29\%) patients were females. In group A, 11 (31.4\%) were men and 24 (68.6\%) were women. Group B had $21(60.0 \%)$ men and 14 (40.0\%) women.

Results mentioned in Table-I showed that the postoperative pain and operating time was markedly decrease in laparoscopic group then open.

According to the stratification of gender and age in Table-II and Table-III also showed that the postoperative pain and operating time was markedly less in group $B$ than group $A$. 


\begin{tabular}{|c|c|c|c|c|c|}
\hline \multirow[b]{2}{*}{ Variables } & \multicolumn{4}{|c|}{ Surgical Approach } & \multirow[b]{2}{*}{ P-Value } \\
\hline & \multicolumn{2}{|c|}{$\begin{array}{l}\text { Open Appendectomy } \\
\qquad(n=35)\end{array}$} & \multicolumn{2}{|c|}{$\begin{array}{l}\text { Laparoscopic Appendectomy } \\
\text { (n=35) }\end{array}$} & \\
\hline Post Operative Pain & \multicolumn{2}{|c|}{$7.34 \pm 2.014$} & \multicolumn{2}{|c|}{$3 \pm 1.94$} & 0.0001 \\
\hline \multirow[t]{2}{*}{ Operative Duration } & \multicolumn{2}{|c|}{$42.33 \pm 4.25$} & \multicolumn{2}{|c|}{$34.48 \pm 3.5$} & 0.0001 \\
\hline & \multicolumn{5}{|c|}{ Table-I. Comparison of post-op pain and operative pain in both groups } \\
\hline \multirow[b]{2}{*}{ Gender } & \multirow[b]{2}{*}{ Variables } & \multicolumn{3}{|c|}{ Surgical Approach } & \multirow[b]{2}{*}{ P-Value } \\
\hline & & $\begin{array}{l}\text { Open App } \\
(n=\end{array}$ & omy & $\begin{array}{l}\text { Laparoscopic Appendectomy } \\
\qquad(n=35)\end{array}$ & \\
\hline \multirow[t]{2}{*}{ Male } & Postop Pain & \multicolumn{2}{|c|}{$7.36 \pm 1.63$} & $3.52 \pm 2.11$ & 0.0001 \\
\hline & Operative duration & \multicolumn{2}{|c|}{$44.26 \pm 3.09$} & $34.89 \pm 3.9$ & 0.0001 \\
\hline \multirow{2}{*}{ Female } & Postop Pain & \multicolumn{2}{|c|}{$7.33 \pm 2.2$} & $2.21 \pm 1.37$ & 0.0001 \\
\hline & Operative duration & \multicolumn{2}{|c|}{$41.44 \pm 4.46$} & $33.87 \pm 2.83$ & 0.0001 \\
\hline \multicolumn{6}{|c|}{ Table-II. Comparison of pain score and operative time for male and female patients } \\
\hline \multirow[b]{2}{*}{ Age Distribution } & \multirow[b]{2}{*}{ Variables } & \multicolumn{3}{|c|}{ Surgical Approach } & \multirow[b]{2}{*}{ P-Value } \\
\hline & & $\begin{array}{l}\text { Open App } \\
\qquad(\mathrm{n}=\end{array}$ & tomy & $\begin{array}{l}\text { Laparoscopic Appendectomy } \\
\qquad(\mathrm{n}=35)\end{array}$ & \\
\hline \multirow{2}{*}{$13-22$ years } & Postop pain & \multicolumn{2}{|c|}{$7.57 \pm 1.45$} & $3.09 \pm 2.3$ & 0.0001 \\
\hline & Operative duration & \multicolumn{2}{|c|}{$44.18 \pm 4.45$} & $35.54 \pm 4.1$ & 0.0001 \\
\hline 23.32 vearc & Post Op pain & $6.5 \pm$ & & $3 \pm 1.91$ & 0.001 \\
\hline 23-3< years & operative duration & 41.33 & & $33.99 \pm 3.64$ & 0.0001 \\
\hline $33-42$ veare & Post Op pain & $8.75=$ & & $3.6 \pm 2.3$ & 0.005 \\
\hline $30-4<$ years & operative duration & 40.19 & & $33.49 \pm 2.81$ & 0.38 \\
\hline 13.52 veare & Post Op pain & $7.67=$ & & $2.25 \pm 1.26$ & 0.002 \\
\hline 43-52 years & operative duration & 40.33 & & $33.21 \pm 2.56$ & 0.015 \\
\hline -50 varr & Post Op pain & $7.5 \pm$ & & $2.5 \pm 0.71$ & 0.189 \\
\hline$>52$ years & operative duration & 42.55 & & $36.83 \pm 0.7$ & 0.065 \\
\hline
\end{tabular}

Table-III. Comparison of pain score and operative time for different age groups

\section{DISCUSSION}

Endoscopy has revolutionized the concept of appendectomy using laparoscope. Study was carried out to compare open appendectomy with laparoscopic appendectomy in terms of postoperative pain and operative duration. Reduce pain sensation after surgery is primary benefit of $\mathrm{LA}^{11}$ versus $\mathrm{OA}$ and is because of less traumatic tissue dissection in laparoscopic appendectomy. Laparoscopic appendectomy is considered as slightly expensive procedure than open appendectomy as it requires specific equipment and longer operative time. It may be associated with increased risk of intra-peritoneal abscess ${ }^{12}$, particularly in patients having perforated appendix and appendicular masses. Longer operative time for laparoscopic appendectomy as shown by previous studies is currently not accepted.
Longer operative time was because of less training in the field of endoscopic surgery ${ }^{13}$ and due to less flexible laparoscopic instruments. Pain (overall level) was markedly low in laparoscopic appendectomy versus open appendectomy $(P$ $=0004$ ). Average postoperative pain according to Visual analogue score at 48 hours for open appendectomy is $4.6 \pm 0.8$ and $1.5 \pm 0.6$ for laparoscopic appendectomy.7,7,14 In another study the mean operative duration was 48.26 +12.02 minutes and in open appendectomy $31.36 \pm 11.43$ minutes, $p<0.001 .^{7,9}$ While in another study the average surgical time was 52.2 min (range: 20-min-155-min) in laparoscopic appendectomy and 49.3 min (range: 20-min$110 \mathrm{~min})$ in open appendectomy $(P<0.476)^{6,7,9,14}$

The results of a systematic review of meta- 
analyses of randomized controlled trials suggested that both operations (laparoscopic and open appendectomy) are reliable and suitable as the surgical management of acute appendicitis. ${ }^{11,15,16,17}$ In this study, time taken in laparoscopic appendectomy was more than in open appendectomy $(P<0.0001)$. The reason for longer duration in laparoscopic approach is mostly less expertise. Duration of hospital admission is considered as important part that mainly affects the financial aspect of the patient. This study concluded that hospital admission was markedly decreased in laparoscopic group $(P=0.015)$, these findings were similar with many researches that concluded a markedly reduced hospital stay for the surgery done by laparoscopy. ${ }^{11,15,18}$

The results of this study showed that patients who underwent laparoscopic appendectomy needed reduced analgesia both intravenous/ intramuscular/oral as compared to open group and this difference was statistically significant $(P<0.001)$. This observation was similar to many other studies ${ }^{12,14,18,19,20}$ that laparoscopic group required less analgesia. The death rate was zero in this research.

Ingroupundergoinglaparoscopicappendectomy, the post-operative morbidity was $6.7 \%$ while in open group morbidity was $24.5 \%$. The incidence of wound infection was markedly raised in group A $(P<0.001)$. In our study four patients from laparoscopic group (4.1\%) developed intra peritoneal pus collection while in open group there was only one patient $(0.32 \%)$. The results of our study are in line with many other studies that in laparoscopic appendectomy the incidence of intra peritoneal pus collection is more than open appendentomy. ${ }^{15,17,21}$

The expensiveness of equipments used in laparoscopy compared to the conventional technique is considered as a hurdle for its frequent use. Laparoscopic appendectomy is slightly expensive than open appendectomy mainly because of reduced hospital stay. Moore and al. also suggested a financial advantage of laparoscopic group from a social point of view that young patients can resume their daily activities early in laparoscopic group. ${ }^{22}$

Laparoscopic appendectomy should be taken as good, reliable and effective technique in presence of expertise and laparoscopic instruments. It may be considered as the first choice in patients undergoing surgery for appendicitis. ${ }^{23,24}$

Currently, there is no gold standard surgical procedure for the treatment of acute appendicitis. Both open and laparoscopic appendectomy enjoy good fame as a method of choice for the treatment of patients with acute appendicitis keeping in view patient wishes, surgical expertise and availability of equipments. ${ }^{25}$ Laparoscopic appendectomy can be first line surgical procedure for the management of acute appendicitis in near future.

\section{CONCLUSION}

Laparoscopic appendectomy is superior to open appendectomy considering pain after surgery and time of surgery in patients with appendicitis. Copyright $(15$ July, 2019.

\section{REFERENCES}

1. Aarabi S, Sidhwa F, Riehle KJ, Chen Q, Mooney DP. Pediatric appendicitis in New England: Epidemiology and outcomes. J Pediatr Surg. 2011; 46(6):1106-14.

2. Podda M, Cillaro N, DiSaverio S, Lai A, Feroci F, Luridiane $G$, et al. Antibiotics first strategy for uncomplicated acute appendicitis in adults is associated with increased rates of peritonitis at surgery. A systematic review with meta-analysis of randomized controlled trials comparing appendectomy and non-operative management with antibiotics. Surgeon. 2017; 15(5):303-14.

3. Addiss DG., Shaffer N, Fowler BS, Tauxe RV. The epidemiology of appendicitis and appendectomy in the United States. Am J Epidemiol. 1990; 132(5):91025.

4. Naraintran S, Sandeep Kumar David S, Raveendran K, Eashwara Billa BK. Comparative study on open appendicectomy versus laparoscopic appendicectomy in a tertiary care centre. Int Surg J. 2018; 5(4):1240-5. 
5. Bansal S, Banever GT, Karrer FM, Partrick DA. Appendicitis in children less than 5 years old: Influence of age on presentation and outcome. Am J Surg. 2012; 204(6):1031-5.

6. Marzuillo P, Germani C, Krauss BS, Barbi E. Appendicitis in children less than five years old: A challenge for the general practitioner. World J Clin Pediatr. 2015; 4(2):19-24.

7. Adwan H, Weerasuriya CK, Endleman P, Barnes A, Stewart L, Justin T. Laparoscopic versus open appendicectomy in children: A UK district general hospital experience. J Pediatr Surg. 2014; 49(2):2779.

8. Khalil J, Muqim R, Rafique M, Khan M. Laparoscopic versus open appendectomy: A comparison of primary outcome measures. Saudi J Gastroenterol. 2011 Jul-Aug; 17(4):236-240.

9. Svensson JF, Patkova B, Almström M, Eaton S, Wester T. Outcome after introduction of laparoscopic appendectomy in children: A cohort study. J Pediatr Surg. 2016; 51(3):449-53.

10. Sheikh AR, Sangrasi AK, Shaikh GA. Clinical outcomes of laparoscopic versus open appendectomy. JSLS. 2009; 13:574-80.

11. Cipe G, Idiz O, Hasbahceci M, Bozkurt S, Kadioglu $H$, Coskun $H$, et al. Laparoscopic versus open appendectomy: Where we are. Chirurgia (Bucur). 2014 Jul-Aug; 109(4):518-22.

12. Kumar S, Jalan A, Patowary BN, Shrestha S. Laparoscopic appendectomy versus open appendectomy for acute appendicitis: A prospective comparative study. Kathmandu Univ Med J (KUMJ). 2016 Jul-Sept; 14(55):244-248.

13. Moher D, Dulberg CS, Wells GA. Statistical power, sample size, and their reporting in randomized controlled trials. JAMA. 1994; 272:122-4.

14. Xiao Y, Shi G, Zhang J, Cao JG, Liu LJ, Chen TH, et al. Surgical site infection after laparoscopic and open appendectomy: A multicenter large consecutive cohort study. Surg Endosc. 2015; 29(6):1384-93.

15. Man E, Nemeth T, Geczi T, Simonka Z, Lazar G. Learning curve after rapid introduction of laparoscopic appendectomy: Are there any risks in surgical resident participation? World J Emerg Surg. 2016 May 3; 11:17.
16. Jaschinski T, Mosch CG, Elkermann M, Neugebaver EA, Sauerland S. Laparoscopic versus open surgery for suspected appendicitis. Cochrane Database Syst Rev 2018 Nov28; 11:CD001546.

17. Lejus C, Delile L, Plattner V, Baron M, Guillou S, Heloury $Y$, et al. Randomized, single blinded trial of laparoscopic vs. Open appendectomy in children: Effects on postoperative analgesia. Anesthesiology. 1996; 84:801-6.

18. Dutta S. Early experience with single incision laparoscopic surgery: Eliminating the scar from abdominal operations. J Pediatr Surg. 2009; 44:17415.

19. Meguerditchian AN, Prasil P, Cloutier R, Leclerc S, Peloguin J, Roy G. Laparoscopic appendectomy in children: A favorable alternative in simple and complicated appendicitis. J Pediatr Surg. 2002; 37:695-8.

20. Zorrón R, Filgueiras M, Maggioni LC, Pombo L, Lopes Carvalho G, Lacerda Oliveira A. Transvaginal cholecystectomy: Report of the first case. Surg Innov. 2007; 14:279-83.

21. Kapischke M, Pries A, Caliebe A. Short term and long-term results after open vs. laparoscopic appendectomy in childhood and adolescence: A subgroup analysis. BMC Pediatr. 2013; 13:154.

22. Moore DE, Speroff T, Grogan E, Poulose B, Holzman MD. Cost perspectives of laparoscopic and open appendectomy. Surg Endosc. 2005; 19:374-8.

23. Minutolo V, Licciardello A, Di Stefano B, Arena M, Arena G, Antonacci V. Outcomes and cost analysis of laparoscopic versus open appendectomy for treatment of acute appendicitis: 4-years experience in a district hospital. BMC Surg. 2014 Mar 19; 14:14.

24. Li X, Zhang J, Sang L, Zhang W, Chu Z, Li X, Liu Y. Laparoscopic versus conventional appendectomy-a meta-analysis of randomized controlled trials. BMC gastroenterology. $2010 \mathrm{Dec} ; 10(1): 129$.

25. Andersson RE. Short-term complications and long-term morbidity of laparoscopic and open appendicectomy in a national cohort. $\mathrm{Br} \mathrm{J}$ Surg Aug; 101(9): 1135-42. 


\section{AUTHORSHIP AND CONTRIBUTION DECLARATION}

\begin{tabular}{|c|c|c|c|}
\hline Sr. \# & Author-s Full Name & Contribution to the paper & Author's Signature \\
\hline 1 & Saddaqat Hayat & $\begin{array}{l}\text { Idea generation, research } \\
\text { work. }\end{array}$ & \\
\hline 2 & Osman Riaz & $\begin{array}{l}\text { Data analysis, manuscript } \\
\text { writing. }\end{array}$ & \\
\hline 3 & Muhammad Usman & Research work. & \\
\hline 4 & M. Faisal Bilal Lodhi & Supervised the research. & \\
\hline 5 & Asrar Ahmad Khan & $\begin{array}{l}\text { Data analysis and } \\
\text { interpretation. }\end{array}$ & \\
\hline
\end{tabular}

